\title{
A comparison of car driving, public transport and cycling experiences in three European cities
}

\author{
Author names and affiliations \\ Woods, Ruth a \& Masthoff, Judith ${ }^{\mathrm{b}}$ \\ a School of Applied Social Studies, Robert Gordon University, Aberdeen, AB10 \\ 7QG, Scotland. r.woods3@rgu.ac.uk \\ b Department of Computing Science, School of Natural and Computing Sciences, \\ University of Aberdeen, Aberdeen, AB24 3FX, Scotland. j.masthoff@abdn.ac.uk \\ Corresponding author \\ Woods, Ruth
}




\section{Abstract}

Private car use in large cities causes congestion and pollution, and should be reduced. Previous research has shown that private cars are preferred over public transport, but it is not known whether that preference holds in large cities that attenuate the usual benefits of car travel. The small body of research comparing cycling with car driving has found a preference for cycling, but it is not clear what that preference is based on, nor its generalizability, particularly beyond those who already cycle frequently. The current study, which was undertaken as part of the EU-funded project, SUPERHUB (SUstainable and PERsuasive Human Users moBility in future cities), compares liking and experiences of car driving, public transport and cycling in three European cities: Barcelona, Helsinki and Milan. Cycling was liked significantly more than car driving and public transport, and was rated significantly more positively than or equivalent to cars on many attributes, including flexibility and reliability, indicating an important role for cycling in the reduction of urban car use. Public transport was rated significantly less positively than car driving for some attributes (e.g. flexibility, reliability) but more positively for others (e.g. value for money, safety), demonstrating that in large cities, the usual advantages of car driving over public transport are considerably attenuated. Almost all these findings were replicated across all three cities, suggesting that they can be generalised. Most city dwellers already use more than one mode regularly, which may support mode change campaigns. In particular, a substantial proportion of car driver commuters already enjoyed cycling on a regular basis, suggesting the potential for mode switching, via multimodality to overcome the obstacle of journey distance.

Key words: cycling; public transport; car; attitude; satisfaction; city 


\section{Introduction}

\subsection{The challenge of cars in cities}

Cars are a ubiquitous aspect of most contemporary societies, seen by many people as a necessity (Mann \& Abraham, 2006), with far reaching implications for our lives, including place of residence, participation in activities, family function and sociability (Featherstone, 2004; Gärling, Gärling \& Loukopoulos, 2002; Jensen, 1999; Sheller, 2004). This extensive use of private vehicles contributes to degradation of the local and global environment in several ways. Motorised transport produces at least one sixth of global anthropogenic carbon emissions, and also emits other pollutants, such as carbon monoxide and nitrogen oxides, that reduce air quality (Greene \& Wegener, 1997). Roads and car parks take up valuable space, and private vehicle use increases noise, congestion and road accidents (Greene \& Wegener, 1997).

Most, if not all of these problems are more serious in urban areas (Batterbury, 2003), especially large cities. It is therefore particularly desirable to reduce private vehicle use in cities, by encouraging people to travel by other, less destructive modes: public transport and active travel. Although also relying on motorized vehicles, public transport can alleviate the problems of private vehicle use through its greater efficiency in transporting large numbers of people per vehicle. Active travel such as cycling is perhaps the most desirable of all, producing little or no air or noise pollution, and providing cardiovascular exercise (Pucher \& Buehler, 2008) with substantial benefits for long term health (Celis-Morales et al., 2017) and consequent financial benefits in the form of healthcare savings (Jarrett et al., 2012). These modes are also very cheap, making them potentially the most equitable modes of travel in cities (Pucher \& Buehler, 2008).

Travel behaviour is based partially on our preferences, attitudes, and perceptions of different modes (Gardner \& Abraham, 2008). So in order to reduce car use in cities, we need to understand people's experiences of, and attitudes towards car driving relative to the alternative modes of public transport and active travel. Our understanding should also take gender into account, as in some countries at least, men drive more than women do (Colley \& 
Buliung, 2016). Of course, attitudes towards transport modes are only part of the explanation as to why any particular journey is made by any given mode (see e.g. Nkurunziza et al., 2012; Tin Tin et al., 2010), but they are nevertheless an important component of transport choice (Bamberg, Ajzen \& Schmidt, 2003).

\subsection{Car driving versus public transport}

Most people enjoy travelling by car more than by public transport (Mann \& Abraham, 2006; Páez \& Whalen, 2010; Turcotte, 2005). Travellers find car travel more exciting than public transport (Anable \& Gatersleben, 2005; Gatersleben \& Uzzell, 2007). Car travel is seen to offer greater privacy, protection, autonomy, freedom and control than public transport (Anable \& Gatersleben, 2005; Beirão \& Cabral, 2007; Ellaway et al., 2003; Mann \& Abraham, 2006; Steg, 2003). Cars are also powerful expressions of personal identity, status, and maturity (Ellaway et al., 2003; Gatersleben, 2007; Mann \& Abraham, 2006; Steg, 2003), in a way that is not usually true of public transport. Car travel is often experienced as cheaper (Anable \& Gatersleben, 2005), more flexible, convenient and predictable (Anable \& Gatersleben, 2005; Beirão \& Cabral, 2007; Steg, 2003), and more comfortable (Beirão \& Cabral, 2007; Steg, 2003) than public transport. Finally, public transport journeys tend to take longer than equivalent private vehicle journeys, and commuters are generally less satisfied with longer commutes (Turcotte, 2005).

Public transport is sometimes viewed more positively than driving on certain dimensions. It was seen as more environmentally friendly and healthy than car travel in one UK study (Anable \& Gatersleben, 2005), and participants in a Portuguese study claimed that public transport was less stressful, more relaxing, cheaper, more sociable and less polluting than car driving (Beirão \& Cabral, 2007). The finding that public transport was perceived in this study as cheaper than car driving differs from Anable and Gatersleben's (2005) study in which participants held the opposite opinion. This contrast demonstrates that some grounds for preferring cars can be reversed. Nevertheless, overall, people tend to prefer car driving, a preference that seems to be based on many different journey attributes, making the problem of mode switching look rather intractable. 
This preference for car travel held true across all the countries in which the research cited above was conducted: Canada (e.g. Turcotte, 2005), the Netherlands (e.g. Steg, 2003), Portugal (e.g. Beirão \& Cabral, 2007) and the UK (e.g. Anable \& Gatersleben, 2005). It is not yet known whether it would hold true in other locations, particularly in large cities where the odds are stacked more in favour of public transport, via the provision of extensive public transport networks and/or via limitations on car travel (for instance, congestion, charges, and parking problems). The only comparative research we could find that was conducted in a large city was Beirão \& Cabral's (2007) qualitative study of public transport and car users in Porto, Portugal. It is noteworthy that this study did find some advantages for public transport over car travel. It is plausible that in large cities, car driving is not preferred over public transport to the same extent as in other (urban, suburban and rural) settings. By recruiting from three large European cities, the current study offers a unique opportunity to assess the extent to which private vehicles are preferred over public transport in settings which (to varying degrees) motivate public transport travel and penalise private cars.

\subsection{Car driving versus cycling}

While public transport is generally seen as inferior to car driving, there is intriguing evidence that the opposite is true of cycling. Three Canadian studies found that cyclists enjoyed their commute more than either car drivers or public transport users (Páez \& Whalen, 2010; Turcotte, 2005; Willis et al., 2013), although they do not tell us why this is so (Willis et al., 2013). Willis et al. (2013) found that cyclists' satisfaction was not related to built environment characteristics (such as intersection density) or trip characteristics (such as distance and slope). Anable and Gatersleben (2005) found that cyclists in the UK experienced their journey as cheaper, less stressful, and more predictable, environmentally friendly, healthy, freeing and exciting than drivers or public transport users did, and as flexible, convenient and controllable as drivers' (although it is unclear whether pairwise comparisons between modes were statistically significant). In another British study, journeys by bicycle were evaluated as more interesting, exciting and relaxing, and less stressful, than other modes. However, cycling was also seen as relatively dangerous, with $44 \%$ 
of cyclists commenting on dangerous aspects of their commuting journey (Gatersleben \& Uzzell, 2007). Finally, Heinen et al. (2011) found that Dutch participants saw cycling as beneficial for the environment, relaxing, cheap and healthy (although no comparison was made with other modes).

These studies suggest that cycling is, at least in some situations, enjoyed more than either car driving or public transport, and that this preference is based on several different journey attributes. These findings are important because they suggest that for many car drivers, switching mode to cycling may be more inviting than to public transport, especially in cities where journey distance is likely to be shorter. It is particularly intriguing that most of the research cited above was carried out in the UK and Canada, countries which have done comparatively little to support and encourage cycling via infrastructure or legislation (Pucher \& Buehler, 2008). This suggests that the preference might be even stronger in countries or cities with substantial investment in cycling provision.

There is a need for research examining how widespread this preference for cycling actually is, particularly because most previous research sought the views only of those who already used the mode, raising the question of how easily non-users can be infected with their enthusiasm. Moreover, at least in countries with relatively low cycling rates, cycling is more common among young adults and males (Aldred, Woodcock \& Goodman, 2016; Singleton \& Goddard, 2016), so studies which solicit the views only of regular cyclists may not be representative of the whole population. In addition, we know less about perceptions and experiences of cycling than we do about other transport modes (Handy, Van Wee \& Kroesen, 2014). While comparisons of experiences of driving and public transport are quite common, comparisons between cycling and other modes are rarer (Gatersleben \& Uzzell, 2007). The current study addresses this gap in the literature, by comparing participants' satisfaction with and experiences of cycling, private and public transport on a range of parameters and in several different cities. It then builds on these findings to consider the potential for mode change amongst city dwelling car drivers. One dimension which we explore in this regard is multi-modality. In more rural settings, drivers tend to travel almost exclusively by car, and many are reluctant to consider 
alternative modes (Anable, 2005). The current research asks whether this is also true of urban settings. If not, then mode switching and multimoral journeys may be more accessible than among diehard drivers.

\subsection{Background to the research}

The current study was conducted as part of the EU-funded project, SUPERHUB (SUstainable and PERsuasive Human Users moBility in future cities), which involved the development of an open source platform and mobile app for planning city travel and encouraging sustainable mode use (Gabrielli et al., 2014; SUPERHUB, n.d.). The project focused upon three European cities, each representing countries in which little published research exists on attitudes to different transport modes: Barcelona in Spain; Helsinki in Finland; and Milan in Italy. A crucial element of the project was the initial collection of data on the existing travel behaviour, attitudes and experiences of inhabitants of the three participating cities.

Including metropolitan areas, Barcelona's population stands around 5 million. Barcelona city's population is around 1.6 million. In the metropolitan area, there are approximately 2.7 inhabitants per private car (Ajuntament de Barcelona, 2011). Trips in the metropolitan area are divided between private vehicles (27.5\%), public transport (39.7\%) and active transport (i.e. walking and cycling; 32.7\%). Like Helsinki and Milan, Barcelona has an extensive public transport system, comprising buses, trams, metro and trains (Ajuntament de Barcelona, 2011). Within the city, there are $159 \mathrm{~km}$ of bicycle paths. There is a bicycle share scheme, 'El bicing', with 6000 bicycles distributes across 420 bike stations. Nevertheless, only around 3\% of journeys are by bicycle (Ajuntament de Barcelona, 2011).

The Helsinki metropolitan area is the smallest of the three cities. It is home to around 1 million people, with approximately 600 thousand of these living in the city itself. HSL (Helsinki's public transport operator) reported that in $2008,40 \%$ of journeys were by private car, $30 \%$ by public transport, $20 \%$ on foot, $8 \%$ by bike, and $2 \%$ by other modes (HSL, 2008). In the Helsinki metropolitan area, there are approximately 2.6 inhabitants per private car (Ajuntament de Barcelona, 2011). There are around 750km of cycle paths 
('Active Cycling in Helsinki', n.d.), but no bicycle share scheme was in operation at the time of the research.

Around 8 million people live in Milan's metropolitan area, of whom 1.3 million live in the city itself. There are approximately 1.8 inhabitants per private car, so car ownership is notably higher than in Barcelona or Helsinki. Indeed, car concentration in Milan is one of the highest in the world (Rotaris et al., 2010). Concerns about the very high pollution levels led to the introduction in 2008 of a charging scheme to enter an $8 \mathrm{~km}^{2}$ area of the city centre (Rotaris et al., 2010). Unusually, this scheme was broadly supported by residents, which may be because unlike most similar schemes (such as London, Stockholm), it was motivated primarily by the desire to reduce pollution rather than congestion (Mattioli et al., 2012). Within the city, 56\% of trips are via public transport, 30\% by private car, $8 \%$ by motorbike and $6 \%$ by bicycle. Of journeys between the city and the metropolitan area, $34 \%$ are by public transport, $59 \%$ by private car, $6 \%$ by motorbike and $1 \%$ by bicycle, with no details given on the modal share of walking (Riazzola \& Sevino, 2014). In the municipality overall, car modal share is 47\% (Arcidiacono et al., 2012). Milan has a bike share scheme, 'BikeMi', comprising over 3000 bikes and around 200 bike stations (Carra, 2014; Riazzola \& Sevino, 2014).

By including these three rather different European cities, we are able to ascertain the extent to which previous research findings on travel experience and preferences in Canada, the Netherlands, Portugal and the UK are consistent in other locations and, particularly, in large cities, thus providing valuable insight into generalizability of our findings in other settings. The current study also seeks to identify which motorists might be most amenable to change their travel behavior.

\section{Method and Materials}

A questionnaire was administered at the start of the EU-funded SUPERHUB project, primarily to gather background information about prevailing attitudes, beliefs and behaviours pertaining to travel in Barcelona, Helsinki and 
Milan. The funders did not influence the study design, the collection, analysis or interpretation of data, or the writing of this article. The questionnaire was adapted from the questionnaire used in the European Union Segment research project (Segment, 2014). It included a range of items on demographics, travel behaviour, travel attitudes and travel experiences. The items which are analysed for this study are described in more detail in section 3 (Results).

In early 2012, residents of Barcelona, Helsinki and Milan were invited to complete the questionnaire. All cities advertised the questionnaire via websites, emails and/or Twitter, and incentives for completion were offered, which varied between cities. Completed questionnaires were submitted online or via email. The cities' recruitment campaigns were broadly similar except that Milan was the only city which recruited via environmental organisations, in addition to other avenues such as public transport websites.

In total, 700 participants completed the questionnaire: 177 in Barcelona, 363 in Helsinki, and 160 in Milan. Some participants did not answer all questions; their data are used where possible. Demographic information regarding gender, age and employment status is provided in Table 1, which reveals that $53 \%$ of the sample was female, although this proportion varied substantially between cities (45\% in Barcelona, 65\% in Helsinki and 34\% in Milan). The modal age group in the Barcelona and Helsinki samples was 25 to 34 years; in Milan, it was 35 to 44 years. More than 20\% of Barcelona's sample were 55 or older, compared to below or around 10\% for Helsinki and Milan respectively. Most participants (79\%) were employed full- or part-time. The mean number of children per household was 0.5 , with $70 \%$ of participants living in households with no children. Most participants held a driving licence (88\%) and had access to a car (72\%) and a bicycle (78\%) for private use.

Demographic differences between cities are at least partially the result of sampling, and do not necessarily represent the demographics of the city overall. Moreover, because it recruited partially via environmental organisations, the Milan sample may not be representative of the city overall. Therefore our analyses do not focus on differences between the cities. However, we do check whether our main findings hold across all three cities in the sample, and note where they do not. 
TABLE 1. DEMOGRAPHICS OF STUDY PARTICIPANIS

\begin{tabular}{|c|c|c|c|c|c|}
\hline \multirow{2}{*}{ Demographic } & & \multicolumn{4}{|c|}{$\%$ of sample } \\
\hline & & Barcelona & Helsinki & Milan & Overall \\
\hline Gender & Female & 44.8 & 64.8 & 34.2 & 53.0 \\
\hline \multirow[t]{6}{*}{ Age (years) } & $18-24$ & 5.4 & 20.9 & 8.2 & 14.5 \\
\hline & $25-34$ & 33.3 & 38.6 & 25.3 & 34.3 \\
\hline & $35-44$ & 30.6 & 19.8 & 34.8 & 25.7 \\
\hline & $45-54$ & 10.2 & 13.5 & 20.9 & 14.5 \\
\hline & $55-64$ & 17.0 & 6.6 & 7.6 & 9.1 \\
\hline & $65-74$ & 3.4 & 0.6 & 3.2 & 1.8 \\
\hline \multirow[t]{4}{*}{ Employment } & $\begin{array}{l}\text { (Self) employed } \\
\text { full time }\end{array}$ & 75.5 & 61.9 & 78.1 & 68.7 \\
\hline & $\begin{array}{l}\text { (Self) employed } \\
\text { part time }\end{array}$ & 10.9 & 10.0 & 9.7 & 10.1 \\
\hline & $\begin{array}{l}\text { Unemployed, } \\
\text { retired or } \\
\text { unwaged }\end{array}$ & 10.2 & 6.4 & 5.7 & 7.2 \\
\hline & Full time student & 3.4 & 21.7 & 6.5 & 14.0 \\
\hline \multirow[t]{4}{*}{$\begin{array}{l}\text { Other } \\
\text { information }\end{array}$} & $\begin{array}{l}\text { Holds a driving } \\
\text { licence }\end{array}$ & 91.5 & 82.2 & 96.9 & 87.9 \\
\hline & $\begin{array}{l}\text { Household } \\
\text { includes } 1+\text { child }\end{array}$ & 36.7 & 26.5 & 32.1 & 30.1 \\
\hline & $\begin{array}{l}\text { Access to car for } \\
\text { private use }\end{array}$ & 86.6 & 53.8 & 92.1 & 71.7 \\
\hline & $\begin{array}{l}\text { Access to bicycle } \\
\text { for private use }\end{array}$ & 54.0 & 87.3 & 82.3 & 77.7 \\
\hline
\end{tabular}

\section{Results}

We begin with background information on the characteristics of participants' main journey, before proceeding to analyses which explore patterns 
in participants' expressed liking of driving, cycling and public transport. Participants' experiences of these modes are then investigated in more depth. Finally, we explore the potential for participants who drive for their main journey to travel via other modes.

Quantitative data were mainly analysed using non-parametric statistical tools since dependent variables were generally based on single Likert scale items, hence at the ordinal level of measurement. Many statistical analyses included pairwise comparisons, and in all cases a Bonferroni correction was made to reduce the likelihood of making a type I error. All statistical analyses incorporated all relevant participants who had completed the necessary items in the questionnaire, hence numbers vary from analysis to analysis (as not all participants completed all items). Age as an independent variable was assigned five levels, with 55 to 64 years and 65 to 74 years combined because of low numbers.

\subsection{Background information}

\subsubsection{Main journey characteristics}

The questionnaire asked participants to name their main mode of travel (defined as the mode used for the greatest distance) for their main journey. Participants whose mode use varied across the year were asked to select the one they had used most recently (during the winter). The main journey was defined as participants' most frequent journey; or if two journeys were as frequent, the one which took the most time. For most participants (91\%), this was the journey to work or study. One hundred participants (15.1\%) drove for their main journey, 412 (62.1\%) took public transport (bus, tram, metro or train), 72 (10.9\%) cycled, and 79 (11.9\%) used various other modes (including walking, car passenger, motorbike and scooter). Figures 1 and 2 summarise the distance and duration of participants' main journey, including only those participants who gave this information (it was missing for $5 \%$ of the sample). More than half of journeys (56\%) were below $10 \mathrm{~km}$. with the modal distance being 1 to $5 \mathrm{~km}$. The modal journey duration was 20 to 30 minutes. Almost half of journeys (47.1\%) lasted less than half an hour. 
FIGURE 1. DISTANCE OF PARTICIPANTS' MAINJOURNEY

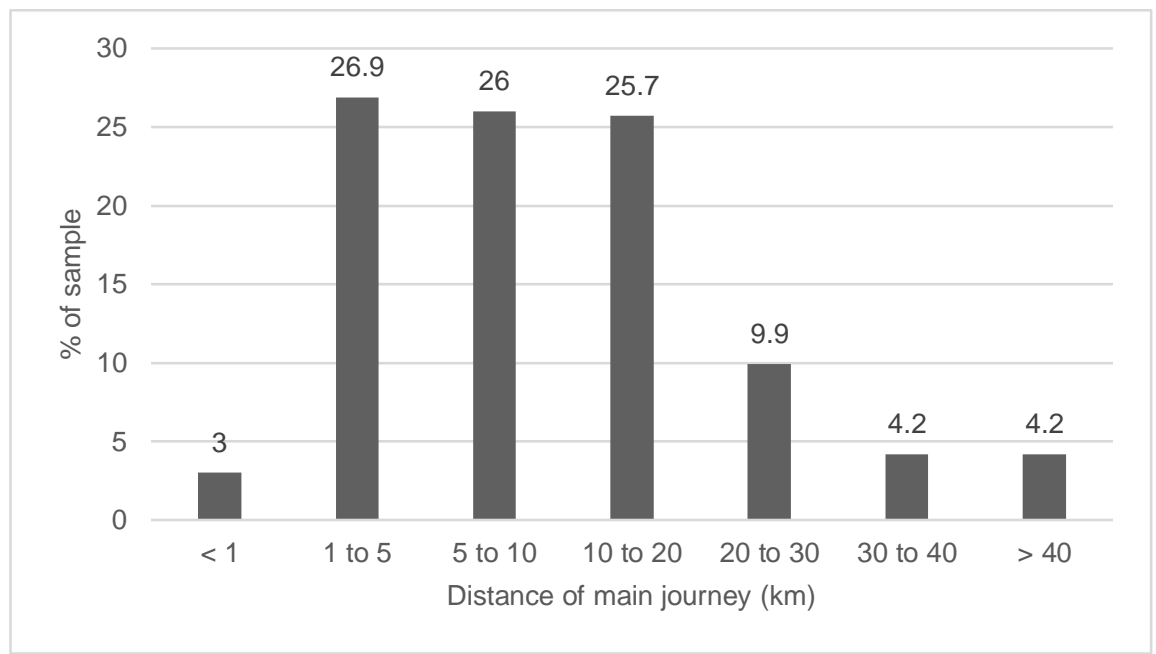

\section{FIGURE 2. DURATION OF PARTICIPANTS' MAINJOURNEY}

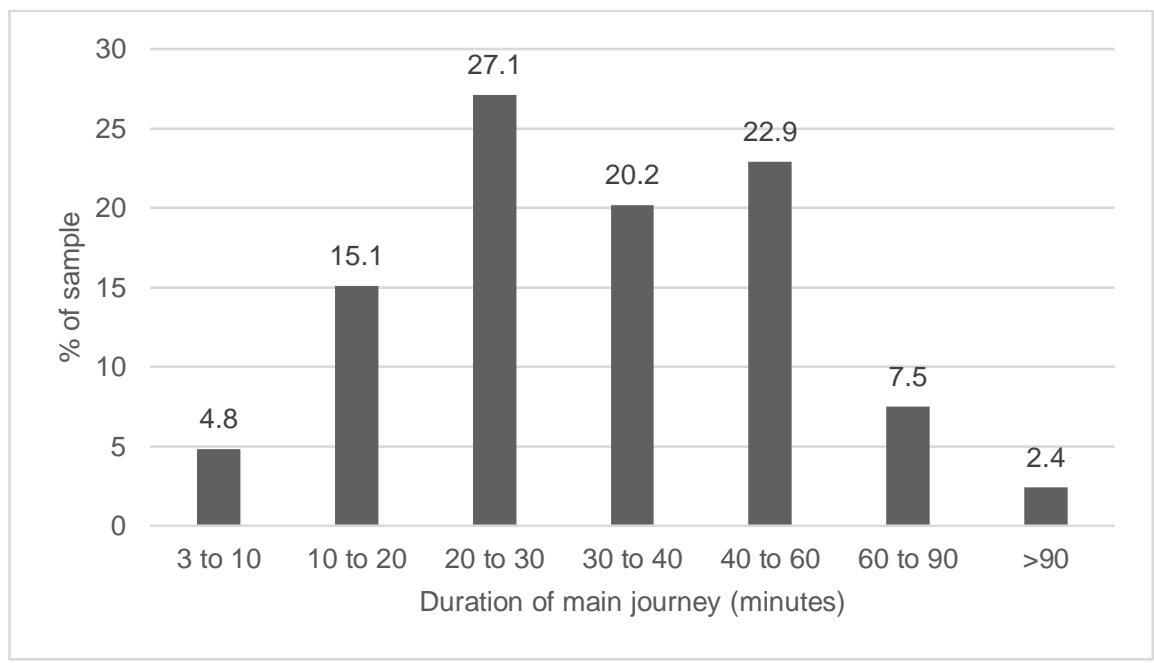

There was a significant association between age and main journey mode, $\chi^{2}(8)=34.569, \mathrm{~N}=583, p<.001$. Driving was over-represented among 35 to 54year-olds; public transport was over-represented among 18-24 and 55+ year olds; and cycling was over-represented among 25-44 year olds. There was also a significant association between gender and main journey mode, $\chi^{2}(2)=10.769$, $\mathrm{N}=574, p=.001$. Men were over-represented among drivers and cyclists, and women among public transport users. 


\subsubsection{Age and gender effects on mode liking}

Liking of each mode was assessed with the question, 'In general, how much do you like travelling by the following types of transport?' Participants completed Likert scale items beginning 'I like travelling by...', with five answer options ranging from `strongly disagree’ (scored as -2) to `strongly agree’ (scored as +2), for car driving, cycling, bus, tram, tube and train travel, and the mean of the latter four items was used as their liking score for public transport.

A non-parametric Kruskall-Wallis analysis of variance found age differences in the extent to which participants liked cycling as a mode of transport, $\chi^{2}(4)=82.212, \mathrm{~N}=657, p=.002$. Ten pairwise comparisons were conducted, so the family-wise $p$ value required for significance was adjusted from .05 to .005 . Those aged 25 to 34 years, and 35 to 44 years, liked cycling significantly more than those aged 55 plus ( $p<.001$ and $\mathrm{p}=.001$ respectively). There were no significant age differences in liking of car driving, $\chi^{2}(4)=2.003$, $\mathrm{N}=654, p=.735$, or public transport, $\chi^{2}(4)=7.332, \mathrm{~N}=652, p=.119$.

Mann-Whitney U-tests found that men liked driving significantly more than women, $U=45174, \mathrm{~N}=645, \mathrm{Z}=2.907, p=.004$. There were no significant gender differences for liking of public transport, $U=49873.5, \mathrm{~N}=642, \mathrm{Z}=.645$, $p=.519$, or cycling, $U=49498, \mathrm{~N}=647, \mathrm{Z}=1.192, p=.233$.

\subsection{Comparisons between liking of driving, public transport and cycling}

A non-parametric Friedman's analysis of variance compared liking scores for car driving, public transport and cycling. This found a significant difference between people's liking of these modes, $\chi^{2}(2)=149.822, \mathrm{~N}=647, p<.001$. Pairwise comparisons found that participants liked cycling significantly more than they liked car driving and public transport (both $p<.001$ ). There was no significant difference between liking of driving and public transport. The percentage of participants asserting that they agreed or agreed strongly that they liked each mode was $44.3 \%$ for driving, 53.2\% for bus travel (used here as a proxy for public transport overall), and $73.8 \%$ for cycling. This widespread liking of cycling extended beyond those who already used this mode regularly; indeed, 
almost half (48\%) of the 289 participants who cycled less than once a month responded that they liked this mode.

Friedman's analyses of variance for each city found the same pattern of preferences in Helsinki, $\chi^{2}(2)=82.212, \mathrm{~N}=355, p<.001$, and Milan, $\chi^{2}(2)=$ 110.065, $\mathrm{N}=154, p<.001$, but not in Barcelona, $\chi^{2}(2)=1.102, \mathrm{~N}=138, p=.603$. This is probably because the Barcelona sample was slightly older than that of the other cities, and it was noted earlier that older participants were less positive about cycling. Excluding those aged 55 and over achieved a result that approached significance for Barcelona residents, with the same pattern as that found in the other cities, $\chi^{2}(2)=4.618, N=111, p=.099$. Pairwise comparisons established that Barcelona participants rated cycling marginally significantly higher than driving $(p=.06)$. Therefore the preference for cycling as a means of travel existed in all three cities among younger participants.

Previous research has shown that attitudes towards a transport mode are correlated with frequency of use of that mode (Abrahamse et al., 2009; Heinen et al., 2011). Although these studies did not establish a causal relationship, it is possible that frequent use of a mode promotes liking. In the current study, less than a third of participants drove or cycled frequently (defined as two or more days per week), compared to over $50 \%$ travelling frequently by bus alone (so we can expect the combined figure for all public transport to be even higher). In an effort to avoid the possible influence of travel frequency, we compared ownmode liking scores of those who travelled by only one of these three modes (car driving, bus, cycling) frequently. (We excluded those participants who travelled frequently on more than one of these three modes, and those participants who did not travel frequently by any of these three modes.)

The resulting Kruskal-Wallis statistical analysis included 322 participants (77 high frequency drivers, 176 high frequency bus travellers, and 69 high frequency cyclists), and found a significant difference between modes, $H(2)=101.163, p<.001$. Pairwise comparisons found that cyclists liked their mode significantly more than car drivers and bus users liked their modes (both $p<.001)$. Car drivers also liked their mode significantly more than bus users did ( $p=.037)$, suggesting that the finding reported above, of no significant difference in liking between public transport and car driving, may be at least partly a 
function of frequency of travel (since the sample included more participants who used public transport frequently than who drove frequently), and that when this is taken into account, car driving may be preferred over public transport (at least bus travel).

It is striking that frequent cyclists' liking scores were close to ceiling. Ninety-four percent of the frequent cyclists who did not travel frequently by car or bus gave their mode the maximum liking score. This compares with $34 \%$ of frequent drivers and $17 \%$ of frequent bus travelers, with respect to driving and public transport liking respectively. This is further evidence that cycling was enjoyed more passionately than other modes of transport.

\subsection{Comparing cyclists', drivers' and public transport users' main journey}

\section{experiences}

Having demonstrated that most participants enjoyed cycling considerably more than driving and public transport, we turn now to investigate the relative appeal of each mode in more detail. These analyses include only those participants who drove, cycled or travelled by public transport for their main journey.

\section{TABLE 3. COMPARING DISTANCE, DURATION AND SATISFACTION FOR PARTICIPANTS' MAINJOURNEYS}

\begin{tabular}{|c|c|c|c|}
\hline $\begin{array}{l}\text { Journey } \\
\text { attribute }\end{array}$ & $\begin{array}{l}\text { Kruskall- } \\
\text { Wallis test } \\
\text { result }\end{array}$ & $\begin{array}{l}\text { Pairwise } \\
\text { comparisons }\end{array}$ & Indicative results \\
\hline Distance & $\begin{array}{l}H(2)=83.773 \\
\mathrm{~N}=582^{* * *}\end{array}$ & $\begin{array}{l}\text { Car }>\mathrm{PT}^{* * *} \\
\text { Car }>\text { cycle }^{* * *} \\
\mathrm{PT}>\text { cycle }^{* * *}\end{array}$ & $\begin{array}{l}\% \text { of journeys that were } 10 \mathrm{~km} \text { or less: } \\
\text { Cars: } 23 \\
\text { Cycles: } 90 \\
\text { PT: } 52\end{array}$ \\
\hline Duration & $\begin{array}{l}H(2)=60.157 \\
\mathrm{~N}=584^{* * *}\end{array}$ & $\begin{array}{l}\text { Cycle }<\text { car }^{* *} \\
\text { Cycle }<\mathrm{PT}^{* * *} \\
\text { Car }<\mathrm{PT}^{* * *}\end{array}$ & $\begin{array}{l}\text { \% of journeys taking } 30 \text { minutes or less: } \\
\text { Car: } 54 \\
\text { Cycle: } 76 \\
\text { PT: } 33\end{array}$ \\
\hline $\begin{array}{l}\text { Satis- } \\
\text { faction }\end{array}$ & $\begin{array}{l}H(2)=22.716 \\
\mathrm{~N}=577^{* * *}\end{array}$ & $\begin{array}{l}\text { Cycle }>\text { car*** }^{* * *} \\
\text { Cycle }>\mathrm{PT}^{* * *} \\
\mathrm{PT}>\text { car* }\end{array}$ & $\begin{array}{l}\text { \% participants who were fairly or very } \\
\text { satisfied with journey: } \\
\text { Car: } 49.5 \\
\text { Cycle: } 81.9 \\
\text { PT: } 65.3\end{array}$ \\
\hline
\end{tabular}


Significance levels are indicated by $*(p<.05), * *(p<.01)$ and $* * *(p<.001)$. Public transport is abbreviated to PT.

Table 3 reveals that cyclists' commutes covered the least distance, followed by public transport, with drivers having the longest journey distances on average. Cycle journeys were also shortest, followed by driving, with public transport providing the longest journey duration. Referring only to their main mode of travel, participants were also asked to give a satisfaction rating for their journey on a 5 point scale ranging from 'very unsatisfied' through to 'very satisfied'. Table 3 shows that cyclists were significantly more satisfied than public transport users and drivers, and that public transport users were also significantly more satisfied than drivers. This pattern of significant differences for distance, duration and satisfaction held across all three cities (all $p<.02$ ) with the exception of satisfaction in Barcelona, where satisfaction scores were ranked in the same order as elsewhere (i.e. cyclists > public transport > driving), but were not significantly different $(p=.409)$.

Participants were asked to rate thirteen aspects of their main mode on their main journey with Likert scales, which were scored as 1 for strongly disagree through to 5 for strongly agree. Drivers', public transport users', and cyclists' ratings were compared using Kruskal-Wallis tests. Results are reported in Table 4.

TABLE 4. COMPARISONS OF CYCLISTS, DRIERS AND PUBLIC TRANSPORT USERS' RATINGS OF THEIR MAINJ OURNEY.

\begin{tabular}{|c|c|c|c|c|c|}
\hline \multirow{2}{*}{$\begin{array}{l}\text { Questionnaire item } \\
\text { I feel that my } \\
\text { journey is } \\
\text { generally... }\end{array}$} & \multicolumn{3}{|c|}{$\begin{array}{l}\text { Median scores and ( } \% \text { of scores } \\
\text { above scale midpoint of } 3 \text { ) }\end{array}$} & \multirow[t]{2}{*}{$\begin{array}{l}\text { Kruskal-Wallis } \\
\text { test results }\end{array}$} & \multirow[t]{2}{*}{$\begin{array}{l}\text { Pairwise } \\
\text { comparisons }\end{array}$} \\
\hline & $\begin{array}{l}\text { Car } \\
\text { drivers }\end{array}$ & PT users & Cyclists & & \\
\hline Stressful & $3(34.4)$ & $2(30.1)$ & $2(15.7)$ & $\begin{array}{l}H(2)=14.758 \\
\mathrm{~N}=574^{* *}\end{array}$ & $\begin{array}{l}\text { Cycle }<\text { car }^{* *} \\
\text { Cycle }<\mathrm{PT}^{* *}\end{array}$ \\
\hline $\begin{array}{l}\text { Good value for } \\
\text { money }\end{array}$ & $3(29.2)$ & $4(59.6)$ & 5 (88.4) & $\begin{array}{l}H(2)=93.112 \\
\mathrm{~N}=573^{* * *}\end{array}$ & $\begin{array}{l}\text { Car }<\text { cycle } \text { cy** }^{* * *} \\
\mathrm{PT}<\text { cycle }^{* * *} \\
\text { Car }<\mathrm{PT}^{* * *}\end{array}$ \\
\hline
\end{tabular}




\begin{tabular}{|c|c|c|c|c|c|}
\hline $\begin{array}{l}\text { Good for the } \\
\text { environment }\end{array}$ & $2(1.1)$ & $4(77.3)$ & 5 (87.3) & $\begin{array}{l}H(2)=221.249 \\
\mathrm{~N}=575^{* * *}\end{array}$ & $\begin{array}{l}\text { Car }<\text { cycle } \text { cy** }^{* * *}<\text { PTcle } \\
\text { Car }<\mathrm{PT}^{* * * *}\end{array}$ \\
\hline Safe & $4(64.2)$ & $4(82.4)$ & $3(40.9)$ & $\begin{array}{l}H(2)=46.707 \\
\mathrm{~N}=574 * * *\end{array}$ & $\begin{array}{l}\text { Cycle }<\text { car* } \\
\text { Cycle }<\mathrm{PT}^{* * *} \\
\text { Car }<\mathrm{PT}^{* *}\end{array}$ \\
\hline Flexible & 4 (83.2) & $4(55.5)$ & $5(97.2)$ & $\begin{array}{l}H(2)=102.113 \\
\mathrm{~N}=574^{* * *}\end{array}$ & $\begin{array}{l}\mathrm{PT}<\text { cycle }^{* * *} \\
\mathrm{PT}<\text { car }^{* * *}\end{array}$ \\
\hline Reliable & 4 (87.1) & $4(59.0)$ & 4 (88.7) & $\begin{array}{l}H(2)=73.880 \\
\mathrm{~N}=574^{* * *}\end{array}$ & $\begin{array}{l}\mathrm{PT}<\text { cycle*** }^{* * *} \\
\mathrm{PT}<\text { car }^{* * *}\end{array}$ \\
\hline $\begin{array}{l}\text { Allows a productive } \\
\text { use of time }\end{array}$ & $4(51.1)$ & $4(58.6)$ & $4(69.0)$ & $\begin{array}{l}H(2)=10.070 \\
\mathrm{~N}=571^{* *}\end{array}$ & $\begin{array}{l}\text { Car }<\text { cycle* } \\
\text { PT }<\text { cycle** }^{* *}\end{array}$ \\
\hline Comfortable & $4(77.1)$ & $3(43.3)$ & $4(67.6)$ & $\begin{array}{l}H(2)=64.096 \\
\mathrm{~N}=578^{* * *}\end{array}$ & $\begin{array}{l}\mathrm{PT}<\text { cycle*** }^{* *} \\
\mathrm{PT}<\text { car }^{* * *}\end{array}$ \\
\hline Sociable & $2(7.4)$ & $3(22.4)$ & $2(25.4)$ & $\begin{array}{l}H(2)=34.002 \\
\mathrm{~N}=575^{* * *}\end{array}$ & $\begin{array}{l}\text { Car }<\text { cycle }^{* *} \\
\text { Car }<\text { PT }^{* * *}\end{array}$ \\
\hline Little effort & $4(59.6)$ & $4(55.0)$ & $4(60.6)$ & $\begin{array}{l}H(2)=8.851 \\
\mathrm{~N}=576^{*}\end{array}$ & $\mathrm{PT}<$ car* \\
\hline Healthy & $2(12.8)$ & $3(32.0)$ & $5(90.1)$ & $\begin{array}{l}H(2)=131.572, \\
\mathrm{~N}=574^{* * *}\end{array}$ & 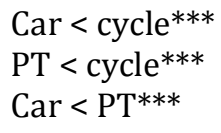 \\
\hline Quick & $4(74.2)$ & $4(50.4)$ & 4.5 (87.5) & $\begin{array}{l}H(2)=83.026 \\
\mathrm{~N}=580^{* * *}\end{array}$ & $\begin{array}{l}\mathrm{PT}<\text { cycle }^{* * *} \\
\mathrm{PT}<\text { car }^{* * *}\end{array}$ \\
\hline Convenient & $4(59.4)$ & $4(65.3)$ & $5(97.2)$ & $\begin{array}{l}H(2)=60.164 \\
\mathrm{~N}=574^{* * *}\end{array}$ & $\begin{array}{l}\text { Car }<\text { cycle }^{* * *} \\
\mathrm{PT}<\text { cycle }^{* * *}\end{array}$ \\
\hline
\end{tabular}

Significance levels are indicated by $*(p<.05), * *(p<.01)$ and $* * *(p<.001)$. Public transport is abbreviated to PT.

Table 4 reveals that relative to car drivers, cyclists evaluated their journey significantly more positively with regards to stress, value for money, environmental impact, productivity, health, convenience and sociability (although levels of sociability were low for all modes). There were no significant differences between cyclists' and drivers' ratings of flexibility, reliability, comfort, effort and speed. Cyclists rated their journey to be significantly less safe than car drivers. 
Public transport users viewed their journey significantly more positively than car drivers with respect to value for money, environment, sociability, safety and health. There were no significant differences between public transport users' and drivers' ratings of stress, productivity and convenience. Public transport was rated significantly lower than driving with respect to flexibility, reliability, comfort, effort and speed.

Cyclists rated their journey significantly more positively than public transport users on almost all attributes: stress, value for money, environment, flexibility, reliability, productivity, comfort, health, speed and convenience. There were no significant differences between cyclists and public transport users for sociability and effort. Cycle journeys were rated as significantly less safe than public transport.

A series of Kruskall-Wallis tests found that significant differences between modes, with the same pattern of differences, held across all cities for all journey attributes (all $p<.04$ ) except for stress in Helsinki, safety in Helsinki, productivity in Barcelona and Milan (no significant difference between modes), sociability in Helsinki (where car driving was rated as more sociable than cycling; $p<.001$ ), and effort in Milan (where car driving was considered more effortful than public transport; $p=.002$ ). In other words, the pattern of differences reported in Table 4 held for individual cities in an impressive 33 of 39 analyses (85\%), suggesting that (aside from productivity), the findings can be generalised to a range of different European cities. The finding of no significant difference between modes in perceptions of safety in Helsinki is particularly noteworthy, because it demonstrates that cycling is not inevitably considered more dangerous than other modes. Of the 21 participants who cycled for their main journey in Helsinki, 14 (66.7\%) rated cycling as safe. While this obviously leaves room for improvement, it is a considerably higher percentage than for Barcelona (40.9\%) and particularly Milan (21.4\%).

\subsection{Exploring mode change possibilities}

Given the positive view of cycling shared by many in the sample, and the relatively low satisfaction ratings of those who drove for their main journey, the 
remainder of the analysis sought to assess the potential for city car drivers to change modes, particularly to cycling.

\subsubsection{Measuring multi-modality}

The analysis begins by considering the extent to which city dwellers utilize multiple modes of travel, rather than always using the same mode. Considering only the main journey, usually to work, $52 \%$ of the sample used only one mode, $31 \%$ used two, $15 \%$ used 3 , and $2 \%$ used four. Therefore almost half of the sample used more than one mode for their most frequent journey. To find out more about participants' multimodality extending beyond their main journey, we asked participants for the average frequency with which they travelled by various modes in the previous year. Multiple mode use is documented in Table 5, which includes only those participants who utilized the four most common modes for their main journey: bicycle, car driving, bus and underground (metro). The table reveals that the vast majority of participants used at least one other mode regularly (once or more per month) in addition to the mode they used to make their main journey. This was slightly less true of main journey drivers than other mode users, but even so, $85 \%$ of those who drove for their main journey travelled by bicycle, bus and/or underground, at least once a month.

TABLE 5. MULTHMDDALIIY OF PARTICIPANIS USING CAR DRING, CYCLING, BUS OR UNDERGROUND ONTHEIR MAINJOURNEY

\begin{tabular}{|c|c|c|c|c|c|}
\hline \multirow[b]{2}{*}{$\begin{array}{l}\text { Main journey } \\
\text { mode }\end{array}$} & \multicolumn{5}{|c|}{$\%$ who travel by various modes at least once a month } \\
\hline & Bicycle & Car & Bus & $\begin{array}{l}\text { Under- } \\
\text { ground }\end{array}$ & $\begin{array}{l}\% \text { using at least } \\
\text { one of these } \\
\text { modes, at least } \\
\text { monthly, in } \\
\text { addition to main } \\
\text { journey mode }\end{array}$ \\
\hline Bicycle $(\mathrm{N}=72)$ & 100 & 38.5 & 71.0 & 71.8 & 95.8 \\
\hline $\operatorname{Car}(\mathrm{N}=100)$ & 50.5 & 100 & 66.7 & 54.5 & 85.0 \\
\hline Bus $(\mathrm{N}=178)$ & 51.2 & 38.5 & 99.4 & 73.5 & 87.6 \\
\hline $\begin{array}{l}\text { Underground } \\
(\mathrm{N}=109)\end{array}$ & 45.3 & 50.5 & 93.5 & 100 & 99.1 \\
\hline
\end{tabular}


Of most interest in terms of mode change potential are those participants who drive cars regularly, so the remainder of this section focuses on those who drive for their main journey.

\subsubsection{Profiling of car drivers}

Table 6 presents a profile of main journey drivers, in terms of various relevant parameters, and compares them with those who already cycle for their main journey. Table 6 reveals that cyclists and drivers in this sample had a similar age and gender profile, and both were generally positive about cycling. In fact, the proportion of drivers who liked cycling (74\%) is similar in size to the proportion who liked driving. However, only around half of main journey drivers cycled at least once a month for transport purposes (compared with 100\% of cyclists), and only $23 \%$ had a journey distance under 10km (compared with $90 \%$ of cyclists). These findings suggest that a lack of recent or regular use, and a long journey, may be important obstacles to drivers contemplating cycling.

\section{TABLE 6. PROFILES OF MAINJOURNEY CAR DRIVERS AND CYCLISTS}

$\begin{array}{lll} & \begin{array}{l}\text { Main journey } \\ \text { cyclists }\end{array} & \begin{array}{l}\text { Main journey } \\ \text { drivers }\end{array} \\ \text { Age }(\%<\mathbf{5 5} \text { years) } & 93.0 & 90.0 \\ \text { Cycle for city transport at least once a month (\%) } & 100 & 50.5 \\ \text { Main journey distance below 10km (\%) } & 90.3 & 23.2 \\ \text { Main journey distance below 20km (\%) } & 98.6 & 63.6 \\ \text { Liking of cycling (\% who agree or strongly agree } & 98.6 & 73.7 \\ \text { that they like cycling) } & & \end{array}$

Fourteen of participants who drove for their main journey (i.e. 14\%) fitted the cyclists' profile in terms of all the attributes included in Table 6: they were aged below 55 years, cycled at least once a month, liked cycling, and had a main journey that was less than $10 \mathrm{~km}$. This figure indicates that a modest proportion of city car drivers meet a range of key criteria for switching from driving to cycling. Of this 'potential cyclists' group, 50\% and 7\% agreed and strongly agreed that they liked driving. The equivalent figures for cyclists liking 
cycling were $21 \%$ and $79 \%$ respectively. This suggests some scope for mode switching to cycling for the main journey.

To establish whether these potential cyclists were discouraged from cycling by concerns about either safety or fitness, we used Mann-Whitney U tests to compare them with participants who cycle for their main journey, on their responses to the Likert scale items, 'Cycling is dangerous' and , 'I tend not to cycle because I am not fit'. It was hypothesized that the potential cyclists would score higher than actual cyclists on both items. The hypothesis was supported with respect to fitness, $U=327.5, \mathrm{~N}=86, Z=2.980$, 1 -tailed $p=.002$, but not danger, $U=468.5, \mathrm{~N}=86, Z=.439$, 1-tailed $p=.330$.

\section{Discussion}

\subsection{Main findings}

The current research is the first to carry out a detailed comparison of driving, cycling and public transport preferences and attitudes in cities, extending our understanding of how these modes are experienced in large scale urban environments. Our discussion reviews our major findings in relation to the literature, and uses them to make a series of recommendations for future research and practice.

Previous research has found that driving is preferred to public transport on almost all parameters that have been measured, including overall enjoyment, flexibility, convenience, comfort, social status and personal expression (Anable \& Gatersleben, 2005; Beirão \& Cabral, 2007; Ellaway et al., 2003; Gatersleben \& Uzzell, 2007; Mann \& Abraham, 2006; Páez \& Whalen, 2010; Steg, 2003; Turcotte, 2005). However, public transport is preferred over cars with respect to environmental impact, healthiness, stress and sociability, with contrasting findings regarding cost (Anable \& Gatersleben, 2005; Beirão \& Cabral, 2007).

In line with previous research, participants in large European cities rated cars more positively than public transport with respect to flexibility, reliability, comfort, effort and speed, and the converse for environmental impact, sociability and health. Public transport was also rated higher than cars for safety and value 
for money, and there was no significant difference for ratings of stress, productivity and convenience. Notably, commuters who used public transport were significantly more satisfied with their journey than were those who drove. In sum, the current study did not find as extensive a preference for car driving as previous studies document, suggesting that in big cities, some of the usual advantages of car driving and disadvantages of public transport are attenuated. However, cars are still seen to have the advantage when it comes to flexibility and reliability, journey attributes which have been identified as particularly important to car drivers in previous research (Anable \& Gatersleben, 2005).

The current study adds to a relatively small body of evidence on experiences of cycling relative to other modes, which has suggested that city cyclists are uniquely passionate about their mode of transport (Anable \& Gatersleben, 2005; Páez \& Whalen, 2010; Turcotte, 2005; Willis et al., 2013). This passion was evident in the current study also, across all three cities (at least amongst the under-55s). Eighty-two percent of those who cycled for their main journey were fairly or very satisfied with their commute, significantly more than the equivalent figures for public transport users (65\%) and drivers (50\%). Furthermore, an impressive $94 \%$ of frequent cyclists agreed strongly that they liked cycling. Compare this with the $34 \%$ of frequent drivers who strongly agreed that they liked driving, and the $17 \%$ of frequent bus users who strongly agreed that they liked travelling by bus.

Our data suggest that this passion is based on multiple dimensions of journey experience. Cycling was seen as significantly less stressful, better value for money, more productive, healthy and convenient, and with a lower environmental impact than both car driving and public transport. These results support previous studies finding that cycle journeys were rated highly, and/or above public transport and cars for cost, stress, predictability, environmental impact, health, excitement and relaxation (Anable \& Gatersleben, 2005; Gatersleben \& Uzzell, 2007; Heinen et al., 2011). Moreover, the current study found that cyclists rated cycling to be as flexible, reliable, fast and comfortable as drivers rated driving, supporting Anable and Gatersleben's (2005) finding that driving and cycling are considered equivalent for flexibility and controllability. The high ratings assigned to cycling were largely replicated across all three sites 
included in the study, suggesting that they are likely to generalise to other European cities too.

\subsection{Recommendations}

Cycling surpassed public transport, and was seen as better than or equal to car travel, on almost all attributes. This makes cycling an exciting proposition for reducing driving in cities, particularly because this study is among the first to demonstrate that liking of cycling extends well beyond those who are already regular cyclists. An impressive $74 \%$ of the whole sample (and 74\% of those who drove for their main journey) liked cycling, significantly more than the numbers who liked car driving (44\%) or public transport (53\%). Further, 48\% of the 289 participants who cycled less than once a month responded that they liked this mode. Given that the questionnaire asked participants to rate cycling as a means of travel as opposed to recreational or leisure cycling, this finding is particularly important in implying that cycle commuting could appeal to a broader demographic than currently uses it regularly. Thirty-two per cent of participants cycled frequently (more than once per week), but only 11\% cycled for their main journey (although note that this figure was obtained during the winter months, so may be higher in other seasons), so there is clear scope for increasing these figures. These findings lead to our first recommendation, which is that efforts to reduce urban car use should focus on increasing cycling.

Examination of the differences between cyclists and drivers suggests that journey distance is an important obstacle to mode switching (although note that the current research cannot demonstrate causation). Cycle journeys were significantly shorter in distance than car and public transport journeys, and only $23 \%$ of drivers had a main journey distance below $10 \mathrm{~km}$ (compared with $90 \%$ of cyclists). While this finding may appear discouraging, it should be considered alongside the finding that multiple mode use was already very much the norm for these city dwellers (with $85 \%$ of those who drove for their main journey also travelling by bicycle, bus and/or underground at least once a month). This starting point of multi-modality is very different from that seen in more rural settings (Anable, 2005), and may make commuting mode change and 
multimodality easier to achieve. We suggest therefore that measures to support and encourage multimodal journeys switching both from and to cycling would be valuable, to enable longer distance travellers to cycle for as much of their journey as possible. It would also be useful to explore whether electric bikes could support an extension of journey distance, as suggested in an American survey (MacArthur, Dill \& Person, 2014).

Another finding was that around half of driver commuters had not cycled at all in the previous month. It is plausible that lack of recent use (along with fitness concerns) may act as an impediment to mode switching. Therefore we recommend campaigns and events which provide adults with the opportunity to practice and (re)gain confidence in cycling as a mode of transport.

A minority of car driver commuters were very similar on various key measures to cycle commuters, raising the question of why they continued to drive. Of course, mode use for any given journey is based on much more than the demographic and journey attributes examined in the current study, and may include many additional influences, including psychological, such as subjective norms and perceived behavioural control (Bamberg et al., 2003; but see Sniehotta, Presseau \& Araújo-Soares, 2014, for a critical perspective), practical (such as time limitations and the need to transport children and/or luggage), and contextual, such as the purpose of the trip (e.g. business versus leisure). There is a need for more research to establish more specifically what prevents car driving city dwellers, particularly those with similar demographics to cyclists, from cycling more regularly. Once barriers have been identified, more targeted transport and marketing measures can be devised.

The one journey attribute on which cycling was rated significantly worse than both driving and public transport was safety. Only $41 \%$ of cyclists agreed that their journey was safe, compared with $64 \%$ of car drivers and $82 \%$ of public transport users. This finding resonates with other studies showing safety to be a concern of cyclists elsewhere too (Gatersleben \& Uzzell, 2007; Hopkinson \& Wardman, 1996). However, within-city analyses found that cycling was not seen as significantly more dangerous than other modes in Helsinki, suggesting that this disadvantage of cycling is not inevitable. 
Many excellent strategies for improving safety have already been devised (Pucher \& Buehler, 2008). Although it did not seem to be a significant concern for the car drivers identified as potential cycle-commuters in the current study, safety can be a deal-breaker for those contemplating cycling (Lorenc et al., 2008; Pooley et al., 2013). Therefore our fifth recommendation is to invest in measures to make cycling safer in cities, drawing on best practice in cities with relatively high safety ratings (such as Helsinki in the current study).

Obviously cycling will not by desirable or possible for some city residents, so there is certainly a role for mode switching from cars to public transport also. While public transport was rated more positively than driving on some attributes, it was as significantly inferior to cars and bicycles with respect to flexibility and reliability, both of which are important to car drivers (Anable \& Gatersleben, 2005). Previous research has found that improving reliability and frequency increases uptake of public transport (Brög \& Erl, 2008; Davison \& Knowles, 2006; Hensher et al., 2010; Levinson et al., 2003; see review by Redman et al., 2013). The corollary is that measures that reduce the flexibility and reliability of car travel (e.g. by restricting parking) may also help to tip the balance in favour of public transport (unpopular as such measures are likely to be). Therefore our final recommendation is that city policies and public transport provision should increase the flexibility and reliability of public transport, particularly relative to car travel.

\subsection{Study limitations and future directions}

There were several limitations to this study. The use of non-parametric statistics made it difficult to evaluate the contribution of confounding variables (such as journey duration) to the significant differences we found, and to uncover interactions between variables. Future work should collect data in a format enabling parametric tests to be used, which can help to identify which of the many variables that differ between cities and samples is responsible for any contrasts in attitudes or experiences, and which are more powerful in uncovering small effect sizes (Aron et al., 2006; Sani \& Todman, 2006). 
Another weakness of the current research is that we did not measure the perceived importance of the different journey attributes (such as cost, environmental impact, flexibility and productivity) we included in our questionnaire. The addition of a measure of importance, such as that included by Anable and Gatersleben (2005), would enable us to identify which mode differences are most influential on people's experiences and mode choice decisions.

In addition, most of the journey attributes included in the current study were instrumental, focused on the practicalities of travel (Steg et al., 2001). Previous research has shown that as well as instrumental functions, emotional and symbolic functions are also important to car drivers (Steg et al., 2001; Gatersleben, 2012), and thus must be taken into account if we are to tempt them onto other modes. So far, there has been little attention to how public transport might emulate the emotional and symbolic dimensions of car use (Redman et al., 2013), and the same is true of cycling.

We did not include any items focusing on symbolic journey attributes, and included only two emotional attributes, stress and sociability. In Barcelona and Milan, cycling was significantly less stressful than driving and public transport, and both cycling and public transport were significantly more sociable than car driving. These results suggest that there is potential for these alternative modes to support positive emotional functions. This may be particularly true of cycling, which was uniquely satisfying in the current study, and which previous research has shown to be pleasurable and/or exciting (Anable \& Gatersleben, 2005; Páez \& Whalen, 2010; Turcotte, 2005; Willis et al., 2013). Moreover, since bicycles are usually privately owned, they may provide more opportunities for self expression than public transport. Future research exploring the emotional and symbolic dimensions of cycling may suggest new ways in which to encourage car drivers to change modes.

To sum up, the current research adds to the limited literature comparing city dwellers' experiences of different travel modes. We uncovered a robust enjoyment of cycling in European cities which surpassed or matched experiences of car driving for every measured aspect except safety. Closer inspection also revealed a demographic which enjoyed cycling yet mainly used a car for 
commuting. Journey distance is likely to be a potentially important obstacle for this group. Since the vast majority already regularly use multiple modes of transport other than the car, there seems considerable scope to overcome the problem of long distance commutes via improved options for multimodal journeys.

\section{Acknowledgements}

This work has been supported by the FP7 IP Project SUPERHUB N. 289067. We are grateful to colleagues who were involved in administering the questionnaire and recruiting participants: Victor Rodriguez Doncel of BDigital (Barcelona), Laura Haverinen and Cristina Viganó of the University of Helsinki (Helsinki), and Annalisa Bortoluzzi, Laura Primerano and Stefania Romano of Legambiente (Milan). We also thank the citizens of Barcelona, Helsinki and Milan who participated in the questionnaire. 


\section{References}

Anable, J. (2005). 'Complacent car addicts' or 'aspiring environmentalists'? Identifying travel behaviour segments using attitude theory. Transport Policy, 12, 65-78.

Abrahamse, W., Steg, L., Gifford, R. \& Vlek, C. (2009). Factors influencing car use for commuting and the intention to reduce it: A question of self interest or morality? Transportation Research Part F, 12, 317-324.

'Active Cycling in Helsinki' (n.d.). Helsinki, Finland. Retrieved from http://www.visithelsinki.fi/en/see-and-experience/activities-inhelsinki/active-cycling-in-helsinki on $5^{\text {th }}$ August 2014.

Ajuntament de Barcelona (2011). Dades Bàsique 2010, v.3. Downloaded from http://w110.bcn.cat/Mobilitat/Continguts/Documents/Fitxers/DadesBasiques2 010Complert.pdf on 22/7/2014.

Aldred, R., Woodcock, J. \& Goodman, A. (2016). Does more cycling mean more diversity in cycling? Transport Reviews, 36, 28-44.

Arcidiatono, A., Galuzzi, P., Pogliani, L., Rota, G., Solero, E. \& Vitillo, P. (2012). Il Piano Urbanistico di Milano (PGT 2012). Italia: Wolters Kluwer.

Anable, J. \& Gatersleben, B. (2005). All work and no play? The role of instrumental and affective factors in work and leisure journeys by different transport modes. Transportation Research Part A, 39, 163-181.

Aron, A., Aron, E.N. \& Coups, E.J. (2006). Statistics for Psychology, 4th Edition. Pearson.

Bamberg, S., Ajzen, I. \& Schmidt, P. (2003). Choice of travel mode in the theory of planned behavior: The roles of past behavior, habit, and reasoned action. Basic \& Applied Social Psychology, 25, 175-187.

Batterbury, S.P.J. (2003). Environmental activism and social networks: campaigning for bicycles and alternative transport in West London. Annals of Political and Social Science, 590, 150-169.

Beirão, G. \& Cabral, J.A.S. (2007). Understanding attitudes towards public transport and private car: A qualitative study. Transport Policy, 14, 6, 478489.

Brög, W. \& Erl, E. (2008). Global problems need global solutions: Behaviour change in three continents. $4^{\text {th }}$ International Symposium on Travel Demand Management, July 16-18, Vienna, Austria.

Carra, I. (2014). BikeMi, obiettivo 50mila abbonati. La Repubblica, 10 ${ }^{\text {th }}$ March 2014.

Celis-Morales, C.A., Lyall, D.M., Welsh, P., Anderson, J., Steell, L., Guo, Y., Maldonado, R., Mackay, D.F., Pell, J.P., Sattar, N. \& Gill, J.M.R. (2017). Association between active commuting and incident cardiovascular disease, cancer, and mortality: prospective cohort study. British Medical Journal, 357, j1456. 
Colley, M. \& Buliung, R.N. (2016). Gender differences in school and work commuting mode through the life cycle: Exploring trends in the greater Toronto and Hamilton area, 1986 to 2011. Transportation Research Record, 2598, 102-109.

Davison, L.J. \& Knowles, R.D. (2006). Bus quality partnerships, modal shifts and traffic decongestion. Journal of Transport Geography, 14, 177-194.

Ellaway, A., Macintyre, S., Hiscock, R. \& Kearns, A. (2003). In the driving seat: psychosocial benefits from private motor vehicle transport compared to public transport. Transportation Research Part F: Traffic Psychology and Behaviour, 6, 3, 217-231.

Featherstone, M. (2004). Automobilities: An introduction. Theory, Culture \& Society, 21, 4, 1-24.

Gabrielli, S., Forbes, P., Jylhä, A., Wells, S., Sirén, M., Hemminki, S., Nurmi, P., Maimone, R., Masthoff, J. \& Jacucci, G. (2014). Design challenges in motivating change for sustainable urban mobility. Computers in Human Behavior, 41, 416-423.

Gardner, B. \& Abraham, C. (2008). Psychological correlates of car use: A metaanalysis. Transportation Research Part F, 11, 300-311.

Gärling, T., Gärling, A. \& Loukopolous, P. (2002). Forecasting psychological consequences of car use reduction: A challenge to an environmental psychology of transportation. Applied Psychology: An International Review, $51,1,90-106$.

Gatersleben, B. (2007). Affective and symbolic aspects of car use: A review. Pages 219 to 234 in T. Gärling and L. Steg (Eds.), Threats to the Quality of Urban Life from Car Traffic: Problems, Causes, and Solutions. Elsevier.

Gatersleben, B. (2012). The psychology of sustainable transport. The Psychologist, 25, 9, 676-679.

Gatersleben, B. \& Uzzell, D. (2007). Affective appraisals of the daily commute. Environment and Behavior, 39, 3, 416-431.

Greene, D.L. \& Wegener, M. (1997). Sustainable transport. Journal of Transport Geography, 5, 3, 177-190.

Handy, S., van Wee, B. \& Kroesen, M. (2014). Promoting cycling for transport: Research needs and challenges. Transport Reviews: A Transnational Transdisciplinary Journal, 34, 1, 4-24.

Heinen, E. \& Handy, S. (2012). Similiarities in attitudes and norms and the effect on bicycle commuting: Evidence from the bicycle cities Davis and Delft. International Journal of Sustainable Transportation, 6, 257-281.

Heinen, E., Maat, K. \& van Wee, B. (2011). The role of attitudes toward characteristics of bicycle commuting on the choice to cycle to work over various distances. Transportation Research Part D, 16, 102-109.

Hensher, D.A., Mulley, C. \& Yahya, N. (2010). Passenger experience with qualityenhanced bus service: the Tyne and Wear 'Superoute' services.

Transportation, 37, 239-256. 
Hopkinson, P. \& Wardman, M. (1996). Evaluating the demand for new cycle facilities. Transport Policy, 3, 4, 241-249.

HSL (2008). Helsinki metropolitan area mobility survey 2008. Downloaded from http://www.hsl.fi/FI/mikaonhsl/julkaisut/Documents/2010/Hgin\%20se udun\%20laajan\%20liiktutk\%20LITU\%202008\%20yhteenveto.pdf on $25 / 4 / 2012$.

Jarrett, J., Woodcock, J., Griffiths, U.K., Chalabi, Z., Edwards, P., Roberts, I. \& Haines, A. (2012). Effect of increasing active travel in urban England and Wales on costs to the National Health Service. Lancet, 379, 2198-2205.

Jensen, M. (1999). Passion and heart in transport: A sociological analysis on transport behaviour. Transport Policy, 6, 1, 19-33.

Levinson, H., Zimmerman, S., Clinger, J., Rutherford, S., Smith, R.L., Cracknell, J. \& Soberman, R. (2003). Bus rapid transit volume 1: Case studies in bus rapid transit. Transport Cooperative Research Program Report 90. Washington DC, USA.

Lorenc, T., Brunton, G., Oliver, S., Oliver, K. \& Oakley, A. (2008). Attitudes to walking and cycling among children, young people and parents: a systematic review. Journal of Epidemiology and Community Health, 62, 852- 857.

MacArthur, J., Dill, J. \& Person, M. (2014). Electric bikes in North America: Results of an online survey. Transportation Research Record, 2468, 123-130.

Mann, E. \& Abraham, C. (2006). The role of affect in UK commuters' travel mode choices: An interpretative phenomenological analysis. British Journal of Psychology, 97, 155-176.

Mattioli, G., Boffi, M. \& Colleoni, M. (2012). Milan's pollution charge: sustainable transport and the politics of evidence. Paper presented at Human Dimensions of Global Environmental Change-Evidence for sustainable development conference, Berlin, $5^{\text {th }}-6^{\text {th }}$ October 2012.

Nkurunziza, A., Zuidgeest, M., Brussel, M. \& Van Maarseveen, M. (2012). Examining the potential for modal change: Motivators and barriers for bicycle commuting in Dar-es-Saleem. Transport Policy, 24, 249-259.

Páez, A. \& Whalen, K. (2010). Enjoyment of commute: A comparison of different transportation modes. Transportation Research Part A: Policy and Practice, 44, 7, 537-549.

Pooley, C.G., Horton, D., Scheldeman, G., Mullen, C., Jones, T., Tight, M., Jopson, A. \& Chisholm, A. (2013). Policies for promoting walking and cycling in England: A view from the street. Transport Policy, 27, 66- 72.

Pucher, J. \& Buehler, R. (2008). Making cycling irresistible: Lessons from the Netherlands, Denmark and Germany. Transport Reviews, 28, 4, 495-528.

Redman, L., Friman, M., Gärling, T. \& Hartig, T. (2013). Quality attributes of public transport that attract car users: A research review. Transport Policy, 25, 119-127. 
Riazzola, S. \& Sevino, V. (2014). Milan SUMP [Sustainable Urban Mobility Plan]: Challenges, strategies and ongoing actions. Paper presented at $1^{\text {st }}$ European Conference on Sustainable Urban Mobility Plans, Sopot, Poland, $12^{\text {th }}$ to $13^{\text {th }}$ June 2014 .

Rotaris, L., Danielis, R., Marcucci, E. \& Massiani, J. (2010). The urban road pricing scheme to curb pollution in Milan, Italy: Description, impacts and preliminary cost-benefit analysis assessment. Transportation Research Part A: Policy and Practice, 44, 5, 359-375.

Sani, F. \& Todman, J. (2006). Experimental Design and Statistics for Psychology: A First Course. Blackwell.

Segment (2014). London Borough of Hounslow surveys. Downloaded from http://www.segmentproject.eu/Hounslow/segment.nsf/Pages/SEG48?OpenDocument on 15/7/2014.

Sheller, M. (2004). Automotive emotions: Feeling the car. Theory, Culture \& Society, 21, 4, 221-242.

Singleton, P. A. \& Goddard, T. (2016). Cycling by choice or necessity? Exploring the gender gap in bicycling in Oregon. Transportation Research Record, 2598, 110-118.

Sniehotta, F. F., Presseau, J. \& Araújo-Soares, V. (2014). Time to retire the theory of planned behavior. Health Psychology Review, 8, 1-7.

Steg, L. (2003). Can public transport compete with the private car? IATSS Research, 27, 2, 27-35.

Steg, L., Vlek, C. \& Slotegraaf, G. (2001). Instrumental-reasoned and symbolicaffective motives for using a motor car. Transportation Research Part F: Traffic Psychology and Behaviour, 4, 151-169.

SUPERHUB (n.d.) About the project. Downloaded from http://www.superhubproject.eu/about.html on 23rd June 2015.

Tin Tin, S., Woodward, A., Thornley, S., Langley, J., Rodgers, A. \& Ameratunga, S. (2010). Cyclists' attitudes toward policies encouraging bicycle travel: Findings from the Taupo Bicycle Study in New Zealand. Health Promotion International, 25, 54-62.

Turcotte, M. (2005). Like commuting? Workers' perceptions of their daily commute. Canadian Social Trends, Statistics Canada, Catalogue No. 11008.

Willis, D.P., Manaugh, K. \& el-Geneidy, A. (2013). Uniquely satisfied: Exploring cyclist satisfaction. Transportation Research Part F, 18, 136-147.

Wunsch, M., Stibe, A., Millonig, A., Seer, S., Dai, C., Schechtner, K. \& Chin, R.C.C. (2015). What makes you bike? Exploring persuasive strategies to encourage low-energy mobility. In T. MacTavish \& S. Basapur (Eds.), Persuasive Technology: Lecture Notes in Computer Science, vol. 9072, pp. 53-64. 